\title{
Trp-Lys-Tyr-Met-Val-Met stimulates phagocytosis via phospho- lipase D-dependent signaling in mouse dendritic cells
}

\author{
Ha-Young Lee ${ }^{1,2}$, Hyun Kyu Kang ${ }^{1}$ \\ Eun Jin $\mathrm{Jo}^{2}$, Jung Im $\mathrm{Kim}^{1,2}$ \\ Youl-Nam Lee ${ }^{1}$, Sang Hwa Lee ${ }^{1}$ \\ Yeong Min Park ${ }^{1}$, Sung Ho Ryu ${ }^{3}$ \\ Jong-Young Kwak ${ }^{1,2}$ and Yoe-Sik Bae ${ }^{1,2,4}$ \\ ${ }^{1}$ Medical Research Center for Cancer Molecular Therapy \\ ${ }^{2}$ Department of Biochemistry \\ College of Medicine, Dong-A University \\ Busan 602-714, Korea \\ ${ }^{3}$ Division of Molecular and Life Sciences \\ Pohang University of Science and Technology \\ Pohang 790-784, Korea \\ ${ }^{4}$ Corresponding author: Tel, 82-51-240-2889; \\ Fax, 82-51-241-6940; E-mail: yoesik@donga.ac.kr
}

Accepted 6 February 2004

Abbreviations: DC, dendritic cell; FRR, formyl peptide receptor; fMLF, N-formyl-methionyl-leucyl-phenylalanine; PBt, phosphatidylbutanol; PKC, protein kinase C; PLD, phospholipase D; PTX, pertussis toxin

\footnotetext{
Abstract

Dendritic cells (DCs) play a key role in activating the immune response against invading pathogens as well as dying cells or tumors. Although the immune response can be initiated by the phagocytic activity by DCs, the molecular mechanism involved in this process has not been fully investigated. Trp-Lys-Tyr-Met-Val-Met-NH $\mathrm{N}_{2}$ (WKYMVM) stimulates the activation of phospholipase D (PLD) via $\mathrm{Ca}^{2+}$ increase and protein kinase $\mathrm{C}$ activation in mouse DC cell line, DC2.4. WKYMVM stimulates the phagocytic activity, which is inhibited in the presence of $\mathrm{N}$-butanol but not $t$-butanol in DC2.4 cells. Furthermore, the addition of phosphatidic acid, an enzymatic product of PLD activity, enhanced the phagocytic activity in DC2.4 cells. Since at least two of formyl peptide receptor (FPR) family (FPR1 and FPR2) are expressed in DC2.4 as well as in mouse bone marrow-derived dendritic cells, this study suggests that the activation of FPR family by WKYMVM stimulates the PLD activity resulting in phagocytic activity in DC2.4 cells.
}

Keywords: chemotactic factors; dendritic cell; $N$-formylmethionine leucyl-phenylalamine; oligopeptides; phagocytosis; phospholipase $D$; receptors, formyl peptid

\section{Introduction}

Dendritic cells (DCs) are well-known dedicated antigen presenting cells, and perform important roles in the regulation of the immune response (Guermonprez et al., 2002; Granucci et al., 2003). During the initiation of the immune response, DCs capture the invading pathogens, dying cells or tumor antigens. After antigen uptake, the DCs process and present the processed peptides on the surface of the DCs inducing the stimulation of naive $T$ cells into antigenspecific immune responses (Guermonprez et al., 2002; Granucci et al., 2003). Since phagocytosis of the antigen by DCs is an initial step for the proper immune responses, it is important to reveal the regulation mechanism of this event. However, the regulation of phagocytic activity as well as the signaling pathways of the event in DCs has not been reported.

Phospholipase D (PLD), which catalyzes the hydrolysis of phosphatidylcholine to generate phosphatidic acid (PA), has been reported to play an important role in the regulation of the immune response by phagocytic cells (Lennartz, 1999; Cockraft, 2001). The potential role(s) for the PLD-generated PA in biological functions of the phagocytic cells is suggested by virtue of the unique enzymatic characteristics of PLD i.e. the transphosphatidylation reaction by which the phosphatidyl moiety of the phospholipid is transferred to a primary alcohol to produce the phosphatidylalcohol at the expense of PA. The presence of the primary alcohol has been reported to interfere with the activation of NADPH oxidase and degranulation (Bae et al., 1999; Giron-Calle and Forman, 2000; Kaldi et al., 2002). Although two isoforms of PLD, PLD1 and PLD2, have been cloned in mammalian cells (Hammond et al., 1995; Colley et al., 1997), little is known regarding the molecular identity of the PLD isoforms expressed in DCs and their roles in activationg the DCs.

The formyl peptide receptor (FPR) family is one of the classical chemoattractant receptors, which are $G$ protein-coupled, and seven trans-membrane receptors. The FPR family receptors have been reported to play an important role in modulating innate immune 
responses in mice (Gao et al., 1999; Hartt et al., 2000; Liang et al., 2000; Tiffany et al., 2001). Activating FPR1 via its specific agonist, $N$-formyl-methionyl-leucyl-phenylalanine (fMLF) induced the chemotactic migration of phagocytic cells, such as monocytes and neutrophils. The fMLF also has been reported to elicit superoxide generation in the mouse neutrophils via FPR1 activation (Fillion et al., 2001; $\mathrm{Li}$ et al., 2002). Regarding the functional roles of FPR2, the amyloid beta peptide has been reported to induce phagocyte chemotaxis and oxidant stress in phagocytes (Tiffany et al., 2001). Although the functional roles of the activation of the FPR family receptors in the neutrophils were extensively studied, their roles in the DCs have not been fully investigated. Recently Yang et al. demonstrated that FPR and FPRL2 are expressed in human immature DCs or mature DCs (Yang et al., 2002). FPRL1 was reportedly down-regulated in human immature DCs and mature DCs (Yang et al., 2001; Yang et al., 2002). On the functional role of FPR and FPRL2 in human DCs, the two receptors are involved in the chemotactic migration of DCs (Yang et al., 2002). However, the expression and function of FPR family in mouse DCs have not been fully investigated until now.

Previously we reported on the synthetic peptide, Trp-Lys-Tyr-Met-Val-Met-CONH 2 (WKYMVM), which can stimulate leukocyte activity (Baek et al., 1996). WKYMVM was found to stimulate phosphoinositide (PI) hydrolysis and extracellular signal-regulated protein kinase (ERK) activation in U937 cells, and these events proved to be PTX-sensitive, suggesting the involvement of PTX-sensitive G-protein (Baek et al., 1999). Recently it was demonstrated that WKYMVM is a ligand for FPR family (FPRL1 and FPRL2 but not FPR) (Christophe et al., 2001). In this study, we investigated the functional role of FPR family using a specific agonist, WKYMVM in the immature DCs, the DC2.4 cells. The major function of the immature DCs is the phagocytosis of pathogens, apoptotic cells, or tumor cells, and we focused on the modulation of phagocytic activity by WKYMVM.

\section{Materials and Methods}

\section{Materials}

WKYMVM was synthesized, purified, and prepared in the Peptide Library Support Facility at Pohang University of Science and Technology, as described previously (Baek et al., 1996). Radioiodinated TrpLys-Tyr-Met-Val-D-Met (WKYMVm) (Seo et al., 1997) $\left(\left[{ }^{125} \mathrm{I}\right]\right.$-labeled) and $\left[9,10(\mathrm{n}){ }^{3} \mathrm{H}\right]$ myristic acid (53 $\mathrm{Ci} / \mathrm{mmol})$ were obtained from Amersham Pharmacia Biotech (Buckinghamshire, UK). fMLF and fluores- cein-conjugated dextran were purchased from Sigma (St. Louis, MO). The precoated silica gel TLC plates (F-254) were obtained from Merck (Darmstadt, FRG). The RPMI 1640 was acquired from Invitrogen Corp. (Carlsbad, CA). Dialyzed FBS and supplemented bovine calf serum were purchased from Hyclone Lab. Inc. (Logan, UT). Fura-2 pentaacetoxymethyl ester (fura-2/AM) and 1, 2-bis (2-aminophenoxy) ethane- $N$, $N, \quad N^{\prime}, \quad N^{\prime}$-tetraacetoxymethylester (BAPTA/AM) were purchased from Molecular Probes (Eugene, OR). 2[1-(3-dimethylaminopropyl)-1 H-indol-3-yl]-3-(1H-indol3-yl)-maleimide (GF109203X), \{3-[1-[3-(amidinothio) propyl-1H-indol-3-yl]-3-(1-methyl-1H-indol-3-yl)maleimi de methane sulfonate (Ro-31-8220), and 2'-amino-3'methoxyflavone (PD98059) were obtained from Calbiochem (San Diego, CA). The antibodies specific to PLD, C-terminal-specific antibodies, were prepared as described previously (Lee et al., 1997).

\section{Cell culture}

The cell line DC2.4, derived from C57BI/6 mice, was originally provided by Dr. Kenneth L. Rock (Division of Lymphocyte Biology, Dana Farber Cancer Institute, Boston, MA) and maintained as previously reported (Shen et al., 1997). The DC2.4 cells have a dendritic morphology, express the dendritic cell-specific markers, the MHC molecules, the co-stimulatory molecules, and have phagocytic activity as well as antigen-presenting capacity (Shen et al., 1997). The cells were maintained at approximately $1 \times 10^{6}$ cells $/ \mathrm{ml}$ under the standard incubator conditions (humidified atmosphere, $95 \%$ air, $5 \% \mathrm{CO}_{2}, 37^{\circ} \mathrm{C}$ ). Primary mouse DCs were prepared as described previously (Shin et al., 2003). Briefly, bone marrow cells were isolated form the femur and tibia of C57BL/6 mice and then, the bone marrow cells were resuspended in RPMI 1640 supplemented with $10 \%$ heat-inactivated FBS, 2 $\mathrm{mM} \mathrm{L-glutamine,} 100 \mathrm{U} / \mathrm{ml}$ penicillin, $100 \mu \mathrm{g} / \mathrm{ml}$ streptomycin, $10 \mathrm{mM}$ HEPES buffer, $50 \mu \mathrm{M}$ 2-mercaptoethanol, $20 \mathrm{ng} / \mathrm{ml}$ murine GM-CSF and $10 \mathrm{ng} / \mathrm{ml}$ murine rIL-4 at $37^{\circ} \mathrm{C}$ in a humidified $5 \% \quad \mathrm{CO}_{2}$ incubator. On day 3 , non-adherent granulocytes and $B$ and $T$ lymphocytes were gently removed, and fresh media were added. On day 6 of culture, released, immature, non-adherent cells with the typical morphological features of DCs were harvested (Shin et al., 2003).

\section{Ligand binding assay}

The ligand binding analysis was performed as described previously (Hu et al., 2001). Briefly, the DC2.4 cells were seeded at $1 \times 10^{5}$ cells per well into a 24 well plate and cultured overnight. After blocking the cells with a blocking buffer (33 mM HEPES, $\mathrm{pH} 7.5$, $0.1 \%$ BSA in RPMI 1640) for $2 \mathrm{~h}$, several concen- 
trations of the labeled WKYMVm was added to the cells in a binding buffer (PBS containing $0.1 \%$ BSA), in the presence or absence of the unlabelled peptides, and incubated for $3 \mathrm{~h}$ at $4^{\circ} \mathrm{C}$ with continuous shaking. The samples were then washed 5 times with ice-cold binding buffer, and $200 \mu$ of a lysis buffer (20 mM Tris, pH 7.5, 1\% Triton X-100) was added to each well. After $20 \mathrm{~min}$ at room temperature, the lysates were collected and counted using a $\gamma$-ray counter (Hu et al., 2001).

\section{RT-PCR analysis}

The mRNA was isolated by using a QIAshredder and an RNeasy kit (Qiagen, Hilden, Germany). mRNA, $\mathrm{M}-\mathrm{MLV}$ reverse transcriptase, and $\mathrm{pd}(\mathrm{N})^{6}$ primers (Invitrogen, Carlsbad, CA) were used to obtain the cDNA. The primers used for the RT-PCR analysis have been reported previously (Wang and Ye, 2002). The sequences of the primer used are as follows; FPR1: sense, 5'-ACAGCCTGTACTTTCGAC-3'; antisense, 5'-CTGGAAGTTAGAGCCCGTTC-3'. FPR2: sense, 5'-GTCAAGATCAACAGAAGAAACC-3'; anti-sense, 5'GGGCTCTCTCAAGACTATAAGG-3'. FPR-rs1: sense, 5'-GGCAACTCTGTTGAGGAAAG-3'; anti-sense, 5'-GGCTCTCGGTAGACGAGA-3'. FPR-rs3: sense, 5'-GGTGTCAATTACCGTGAGC-3'; anti-sense, 5'-CTCTCTAAATTCTTGACCAAGAAAG-3'. FPR-rs4: sense, 5'-AGATGTCTGTTATTGCTGCC-3'; anti-sense, 5'-CAGTGTCTCATTGTTAAAGATGTTG -3'. FPR-rs5: sense, 5 '-A CAATTAAAGG TATTCTTTACTGTGAAC-3'; anti-sense, 5'-GCGAATTCTCCTCAGGGCCTACTCTTC-3'. FPR-rs6: sense, 5'-CCCCTGAGGAGCAAGTAAAAGTAT-3'; anti-sense, 5'-CAGGGCTGAGTCCTCCCTTA-3'. FPR-rs7: sense, 5'-CCTGAGGAGCAGGTAAACATGT-3'; anti-sense, 5'-GGGCTGAATCCTCCCTCA-3'. Actin: sense, 5'-ATGGATGATGATATCGCCGCG-3', anti-sense, 5'-TCTCCATGTCGTCCCAGTTG$3^{\prime}$. Forty PCR cycles were run at $94^{\circ} \mathrm{C}$ (denaturation, $30 \mathrm{~s}$ ), $61^{\circ} \mathrm{C}$ (annealing, $30 \mathrm{~s}$ ), and $72^{\circ} \mathrm{C}$ (extension, $30 \mathrm{~s}$ ). The PCR products were electrophoresed on a $2 \%$ agarose gel and visualized by ethidium bromide staining.

\section{Measurement of intracellular calcium concentration}

The intracellular calcium concentration $\left(\left[\mathrm{Ca}^{2+}\right]_{\mathrm{i}}\right)$ was determined using fura-2/AM as described before (Bae et al., 2001a). Briefly, the prepared cells were incubated with $3 \mu \mathrm{M}$ fura-2/AM at $37^{\circ} \mathrm{C}$ for $50 \mathrm{~min}$ in fresh serum free RPMI 1640 with continuous stirring. $2 \times 10^{6}$ cells were aliquoted for each assay in $\mathrm{Ca}^{2+}$ free Locke's solution (154 mM NaCl, 5.6 mM $\mathrm{KCl}, 1.2 \mathrm{mM} \mathrm{MgCl}_{2}, 5 \mathrm{mM}$ HEPES, $\mathrm{pH} 7.3,10 \mathrm{mM}$ glucose, and $0.2 \mathrm{mM} E G T A)$. The fluorescence changes at the dual excitation wavelengths of $340 \mathrm{~nm}$ and $380 \mathrm{~nm}$ as well as the emission wavelength of $500 \mathrm{~nm}$ were measured. The calibrated fluorescence ratio was translated into $\left[\mathrm{Ca}^{2+}\right]$.

\section{Measurement of phosphatidylbutanol formation}

The production of phosphatidylbutanol (PBt) was determined using a slight modification of the method previously reported (Bae et al., 2001b; Kim et al., 2003). The DC2.4 cells were seeded at $1 \times 10^{6}$ cells/ $\mathrm{ml}$ in RPMI 1640 containing 10\% FBS, and the cells were cultured for $20 \mathrm{~h}$ with serum free RPMI1640. The cells were then loaded with $\left.{ }^{3} \mathrm{H}\right]$-myristic acid $(5$ $\mu \mathrm{Ci} / \mathrm{ml}$ ) for $4 \mathrm{~h}$ at $37^{\circ} \mathrm{C}$. The loaded DC2.4 cells were then washed twice with serum-free RPMI 1640 and stimulated with the peptide in the presence of $0.5 \%$ $\mathrm{n}$-butanol. After $30 \mathrm{~min}$, the reactions were quenched by adding $0.5 \mathrm{ml}$ ice-cold methanol, which was followed by aspirating the medium. After adding 0.5 $\mathrm{ml}$ of chloroform and $0.5 \mathrm{ml}$ of $1 \mathrm{M} \mathrm{NaCl}$, the total lipids were extracted by vigorous vortexing. The lower phase obtained after centrifugation at $550 \mathrm{~g}$ for 10 min was dried under nitrogen gas. The lipids were then dissolved in chloroform: methanol (95:5), spotted onto silica gel 60 TLC plates, and separated using a solvent containing chloroform: methanol: acetic acid (90: 10: 10) as described previously (Bae et al., $2001 \mathrm{~b})$. In order to determine the quantity of PBt and the total lipids, a Fuji BAS-2000 image analyzer (Fuji Film Co., LTD) was used.

\section{Immunoprecipitation}

The cultured DC 2.4 cells were lysed in lysis buffer (20 mM Tris- $\mathrm{HCl}, \mathrm{pH} 7.2,10 \%$ glycerol, $150 \mathrm{mM}$ $\mathrm{NaCl}, 1 \%$ Triton $\mathrm{X}-100,1 \%$ cholic acid, $1 \mathrm{mM}$ $\mathrm{Na}_{3} \mathrm{VO}_{4}, 50 \mathrm{mM} \mathrm{NaF}, 10 \mu \mathrm{g} / \mathrm{ml}$ leupeptin, and $1 \mathrm{mM}$ phenylmethylsulfonylfluoride), and proteins were harvested by centrifugation at $4^{\circ} \mathrm{C}$ for $5 \mathrm{~min}$ at 20,000 g. For immunoprecipitation, protein A-Sepharose coupled to anti-PLD antibody $(5 \mu \mathrm{g})$, which is specific to C-terminal of PLD and recognizes both PLD1 and PLD2 (Lee et al., 1997), was incubated with the cell lysate $(2 \mathrm{mg})$ for $4 \mathrm{~h}$ at $4^{\circ} \mathrm{C}$. The immune complexes were then washed five times with lysis buffer, and the immunoprecipitated proteins were released by heating at $95^{\circ} \mathrm{C}$ for $5 \mathrm{~min}$ in Laemmli sample buffer before electrophoresis and immunoblot analysis with antiPLD antibodies: C-terminal-specific antibodies.

\section{Electrophoresis and immunoblot analysis}

The protein samples were prepared for electrophoresis. The proteins in the samples were then separated in an $8 \%$ SDS-polyacrylamide gel using the buffer system described by Laemmli (King and Laemmli, 1971; Kim et al., 2003). Following electro- 
phoresis, the proteins were blotted onto a nitrocellulose membrane, which were then blocked by incubating them with TBST (Tris-buffered saline, $0.05 \%$ Tween-20) containing 5\% non-fat dry milk. Subsequently, the membranes were incubated with the specific antibodies indicated and then washed with TBST. The antigen-antibody complexes were visualized after incubating the membrane with 1:5,000 diluted goat anti-rabbit $\lg G$ or goat anti-mouse $\lg G$ antibodies coupled with horseradish peroxidase. The complexes were then detected by enhanced chemiluminescence.

\section{Measurement of phagocytosis of FITC-dextran by DCs}

The phagocytic activity of the DCs was measured as described previously (Xia and Kao, 2002). DC2.4 cells $\left(1 \times 10^{5}\right)$ were incubated with $1 \mathrm{mg} / \mathrm{ml}$ of FITC-dextran in $500 \mu$ of PBS containing $1 \%$ human serum at $37^{\circ} \mathrm{C}$ for various lengths of time periods. The reaction was quenched by adding $2 \mathrm{ml}$ of ice-cold PBS containing $1 \%$ human serum and $0.02 \%$ sodium azide. The samples were washed three times with ice-cold PBS and analyzed by using a FACScan flow cytometer.

\section{Results}

\section{DC2.4 cells express cell surface receptor(s) for WKYMVm}

Initially, the expression of FPR family proteins in the DC2.4 cells was investigated by using $\left[{ }^{125} \mathrm{I}\right]$-labeled WKYMVm, a specific ligand for FPR family (FPR, FPRL1, and FPRL2) (Le et al., 1999; He et al., 2000; Christophe et al., 2001). The DC2.4 cells were incubated with various concentrations of $\left[{ }^{125} \mathrm{I}\right]$-labeled WKYMVm in the presence or absence of excess of the unlabeled WKYMVm, WKYMVM, or fMLF. As shown in Figure $1 \mathrm{~A}$, the specific binding of $\left[{ }^{125} \mathrm{I}\right]-$ labeled WKYMVm was observed showing the saturation mode. When the ligand binding assays were performed in the presence of several concentrations of the unlabeled WKYMVM, or fMLF, specific binding of the $\left[^{125} \mathrm{I}\right]$-labeled WKYMVm was partially inhibited concentration-dependently (Figure 1B). However, the addition of a combination of unlabeled WKYMVM and fMLF caused an inhibition of $\left[{ }^{125} \mathrm{I}\right]$-labeled WKYMVm binding on DC2.4 cells at the level comparable with that of unlabeled WKYMVm (Figure 1B). These results suggest that the DC2.4 cells express at least two different cell surface receptors for WKYMVm, and one of them is shared by WKYMVM and the other is shared by $\mathrm{FMLF}$.
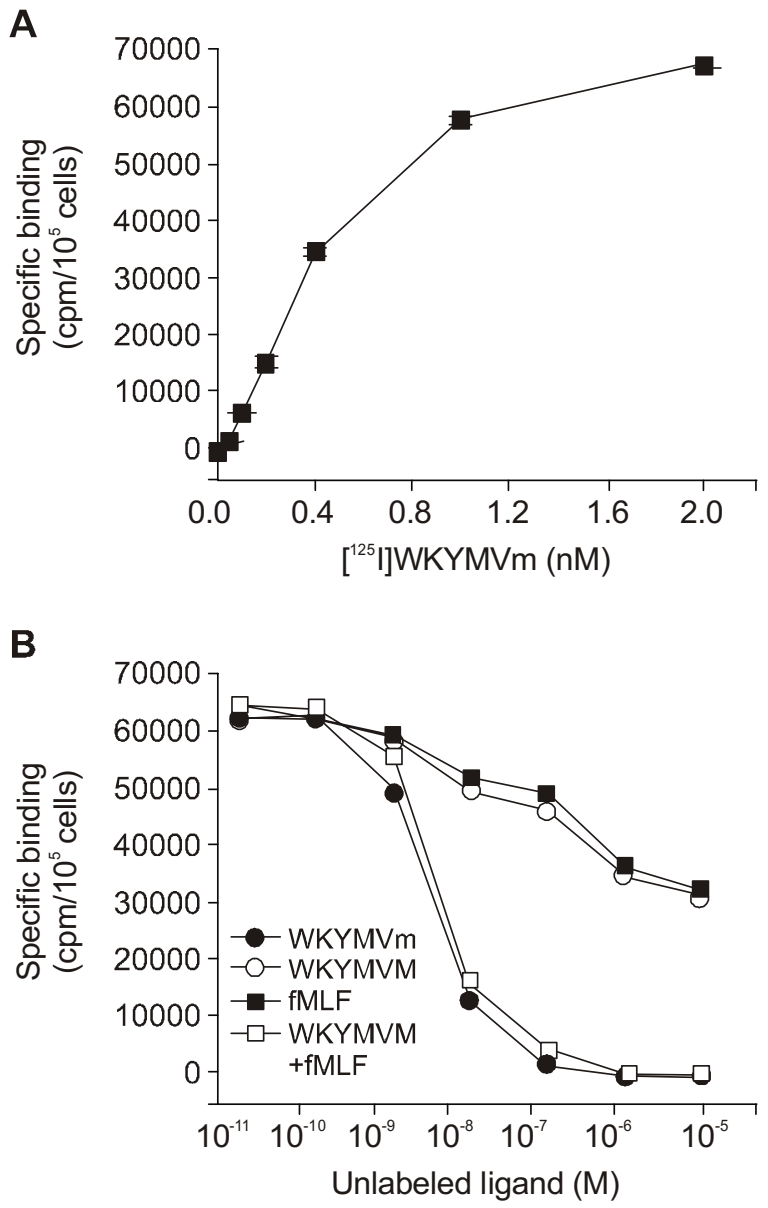

Figure 1. Expression of WKYMVm receptors in the DC2.4 cells. Several concentrations of $\left[^{125} \mathrm{I}\right]$-labeled WKYMVm was incubated with the DC2.4 cells for $3 \mathrm{~h}$ at $4^{\circ} \mathrm{C}$ in the presence or absence of 10 $\mu \mathrm{M}$ of unlabeled WKYMVm (A). $\left.{ }^{125} \mathrm{I}\right]$-labeled WKYMVm $2 \mathrm{nM}$ was incubated with the DC2.4 cells for $3 \mathrm{~h}$ at $4^{\circ} \mathrm{C}$ in the presence or several concentrations of unlabeled ligands, WKYMVm, WKYMVM, or fMLF (B) The level of the specific binding of $\left[{ }^{125}\right.$ ] $]$-labeled WKYMVm was determined using a $\gamma$-ray counter. The results are presented as means \pm S.E. of three independent experiments $(A)$. In panel $B$, the data are representative of three independent experiments, which showed similar results.

\section{DC2.4 cells express FPR1 and FPR2}

WKYMVm was reported to bind FPR, FPRL1, and FPRL2 in human leukocytes (Le et al., 1999; He et al., 2000; Christophe et al., 2001). The expression of mRNA for the different FPR family receptors in the DC2.4 cells was analyzed to identify different receptors by using semiquantitative RT-PCR analysis. As shown in Figure 2, the DC2.4 cells expressed both FPR1 and FPR2 but not the other FPR family. This correlates with the ligand binding analysis that showed the existence of multiple receptors for WKYMVm in the DC2.4 cells. 


\section{WKYMVM stimulates $\left[\mathrm{Ca}^{2+}\right]_{i}$ increase in DC2.4 cells}

Receptor function of both FPR1 and FPR2 expressed in the DC2.4 cells were examined by monitoring the increase in the $\left[\mathrm{Ca}^{2+}\right]_{i}$ by specific ligand. When the DC2.4 cells were stimulated with several concentrations of WKYMVM, an increase in $\left[\mathrm{Ca}^{2+}\right]_{i}$ was evoked in a concentration-dependent manner (Figure 3). The maximum activity was attained at $100 \mathrm{nM}$ WKYMVM (Figure 3). 100 nM WKYMVM elicited flux of approximately $150 \mathrm{nM} \mathrm{Ca}{ }^{2+}$ in the DC2.4 cells (Figure 3). FPR2 is reported to be linked to pertussis toxin (PTX)-sensitive G-protein coupled receptors (Tiffany et al., 2001). Examination of the PTX effect on the WKYMVM-induced $\left[\mathrm{Ca}^{2+}\right]_{\mathrm{i}}$ increase in DC2.4

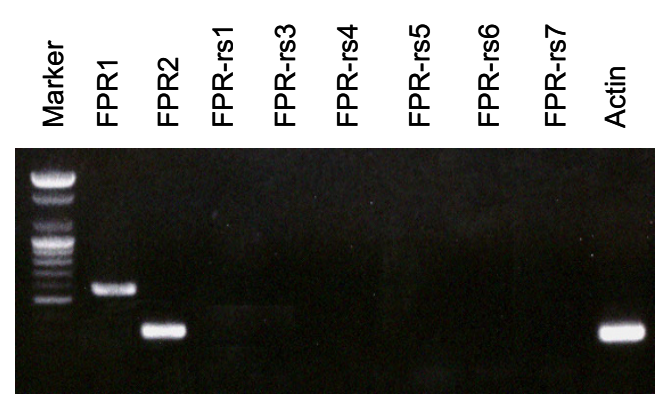

Figure 2. RT-PCR analysis of FPR family receptors in the DC2.4 cells. RT-PCR analysis was performed on the mRNA isolated from the cultured DC2.4 cells, as described in "Materials and Methods." The result presented is representative of three independent experiments.

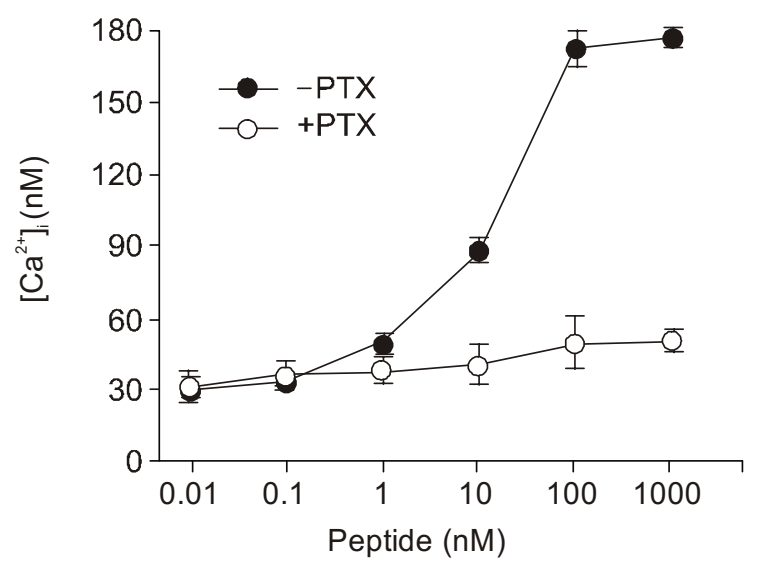

Figure 3. WKYMVM-induced cytosolic calcium increase in the DC2.4 cells. The DC2.4 cells were stimulated with various concentrations of WKYMVM in the presence or absence of PTX (100 ng/ml, $24 \mathrm{~h})$, and the $\left[\mathrm{Ca}^{2+}\right]_{i}$ was determined fluorometrically using fura-2/AM as described in "Materials and Methods". The peak $\left[\mathrm{Ca}^{2+}\right]_{i}$ was monitored. The results are expressed as means \pm S.E. of four independent experiments. cells showed (Figure 3 ) that the cells preincubated with $100 \mathrm{ng} / \mathrm{ml}$ of PTX for $20 \mathrm{~h}$ caused the complete abolishment of WKYMVM induced $\left[\mathrm{Ca}^{2+}\right]_{i}$ flux. This result suggests that the DC2.4 cells express the functional FPR2, and the receptor can be activated by WKYMVM in a PTX-sensitive manner. FMLF also induced the increase in $\left[\mathrm{Ca}^{2+}\right]_{i}$ in a concentrationdependent manner showing PTX-sensitivity (data not shown). Since WKYMVM-induced $\left[\mathrm{Ca}^{2+}\right]_{i}$ increase was more potent than fMLF-induced one (data not shown), in this study, we focused the effect of WKYMVM on the functional modulation of DC2.4 cells.
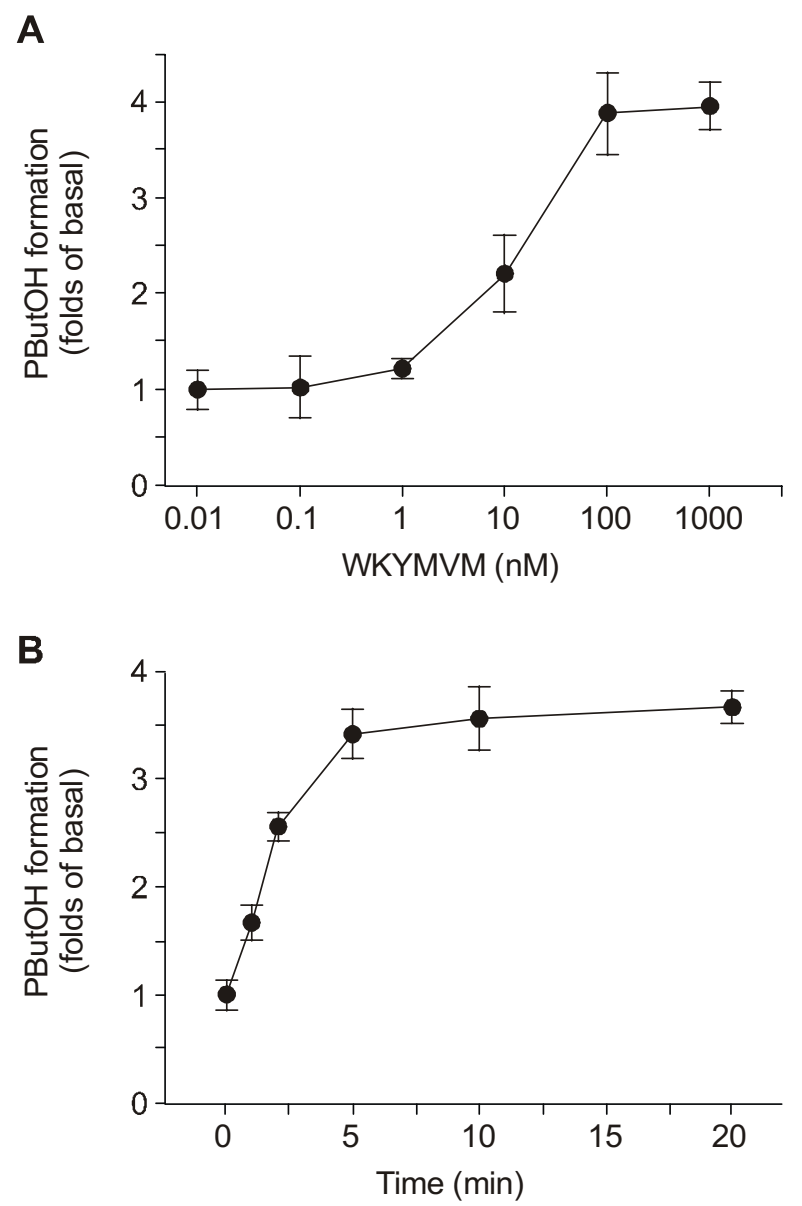

Figure 4. Activation of PLD by WKYMVM in the DC2.4 cells. The cultured DC2.4 cells were labeled with $\left[{ }^{3} \mathrm{H}\right]$ myristic acid for $4 \mathrm{~h}$ at $37^{\circ} \mathrm{C}$ in RPMI 1640. After washing 3 times with PBS, the labeled cells were stimulated with various concentrations of WKYMVM in the presence of $0.5 \%$ n-butanol for $10 \mathrm{~min}(\mathrm{~A})$ or with $1 \mu \mathrm{M}$ of WKYMVM in the presence of $0.5 \%$ n-butanol for various time periods (B). PBt was resolved from the total lipids by thin layer chromatography. After chromatography, the PBt region was scrapped off and the radioactivity was counted. The data are presented as means \pm S.E. from three separate experiments. 


\section{WKYMVM stimulates PLD activation via protein kinase $C$ (PKC)- and $\mathrm{Ca}^{2+}$-dependent signaling in DC2.4 cells}

PLD is regarded as a key enzyme that is involved in the modulation of several functions in leukocytic cells (Milella et al., 1999; Bae et al., 2000; Melendez et al., 2001). Examination of WKYMVM effect on the PLD activation in the DC2.4 cells was carried out by using transphosphatidylation, a characteristic reaction of PLD in the presence of $0.5 \%$ normal butanol (n-butanol). WKYMVM stimulated the formation of PBt in a concentration dependent manner with maximum activity at $100 \mathrm{nM}$ (Figure 4A). The kinetics of PBt formation with $1 \mu \mathrm{M}$ WKYMVM showed that PBt formation was dramatically increased within $1 \mathrm{~min}$

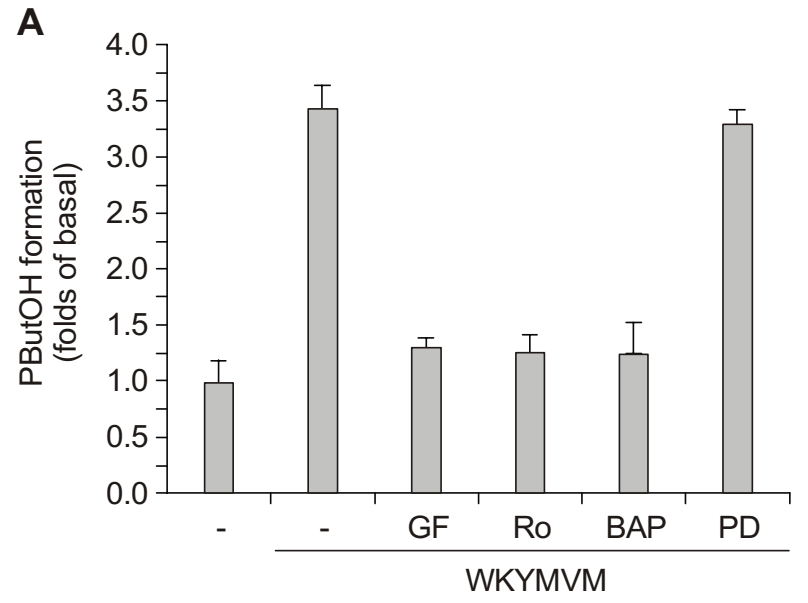

B

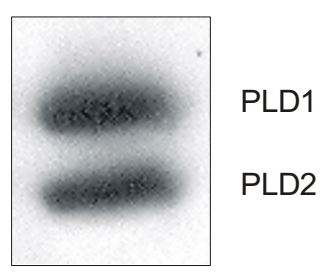

Figure 5. PKC-dependent PLD activation in the WKYMVM-treated DC2.4 cells and the immunological identification of PLD in the DC2.4 cells. The DC2.4 cells preloaded with $\left.{ }^{3} \mathrm{H}\right]$ myristic acid were preincubated with GF109203X (5 $\mu \mathrm{M})$, Ro-31-8220 $(5 \mu \mathrm{M})$, BAPTA/AM (10 $\mu \mathrm{M}), \operatorname{PD} 98059(50 \mu \mathrm{M})$ or the vehicle only for $15 \mathrm{~min}$ at $37^{\circ} \mathrm{C}$ prior to stimulation with $1 \mu \mathrm{M}$ WKYMVM in the presence of $0.5 \%$ n-butanol. The PBt was then separated from the total lipids by thin-layer chromatography. The Fuji BAS-2000 instrument was used to quantify each lipid. The data represent means \pm S.E. from three separate experiments (A). The freshly cultured DC2.4 cells were lysed in a lysis buffer $(20 \mathrm{mM}$ Tris- $\mathrm{HCl}, \mathrm{pH} 7.2,10 \%$ glycerol, $150 \mathrm{mM} \mathrm{NaCl}, 1 \%$ Triton X-100,1\% cholic acid, $1 \mathrm{mM} \mathrm{Na} \mathrm{VO}_{4}, 50 \mathrm{mM} \mathrm{NaF}, 10 \mu \mathrm{g} / \mathrm{ml}$ leupeptin, and $1 \mathrm{mM}$ phenylmethylsulfonyl fluoride), and $2 \mathrm{mg}$ aliquots of the cell lysate were subjected to immunoprecipitation with protein A-Sepharose coupled to the C-terminal-specific antibodies followed by immunobloting with the anti-C-terminal-specific antibodies (B). after stimulation and reached a plateau at $5 \mathrm{~min}$ (Figure 4B).

To investigate the signaling pathway leading to PLD activation by WKYMVM, the role of PKC in the process was examined. Preincubation of the DC2.4 cells with an effective concentration $(5 \mu \mathrm{M})$ of the two PKC-inhibitors (Ro-31-8220 or GF109203X) prior to stimulation with WKYMVM blocked the PLD catalyzed PBt formation (Figure 5A). The peptide-stimulated PLD activity was almost completely inhibited when the DC2.4 cells were preincubated with $10 \mu \mathrm{M}$ BAPTA/ AM prior to stimulation with WKYMVM (Figure 5A). However, pretreating the cells with PD98059 did not affect the PLD activity induced by WKYMVM (Figure $5 A)$. Such results suggest that WKYMVM stimulates the PLD activation in a PKC- and $\mathrm{Ca}^{2+}$-dependent manner in the DC2.4 cells.

\section{DC2.4 cells express PLD1 and PLD2}

The identity of PLD isoform, which might be involved in the WKYMVM-dependent PBt formation in the DC 2.4 cells, was scrutinized using PLD antibodies: C-terminal-specific antibodies, as the immunological probes. The treated cell lysate was immunoprecipitated with Protein A Sepharose coupled to the C-terminal-specific antibodies that can react with both of the PLD1 and PLD2 (Lee et al., 1997) and followed by immunoblotting analysis with the C-terminal PLD antibodies. Both PLD1 and PLD2 were identified in

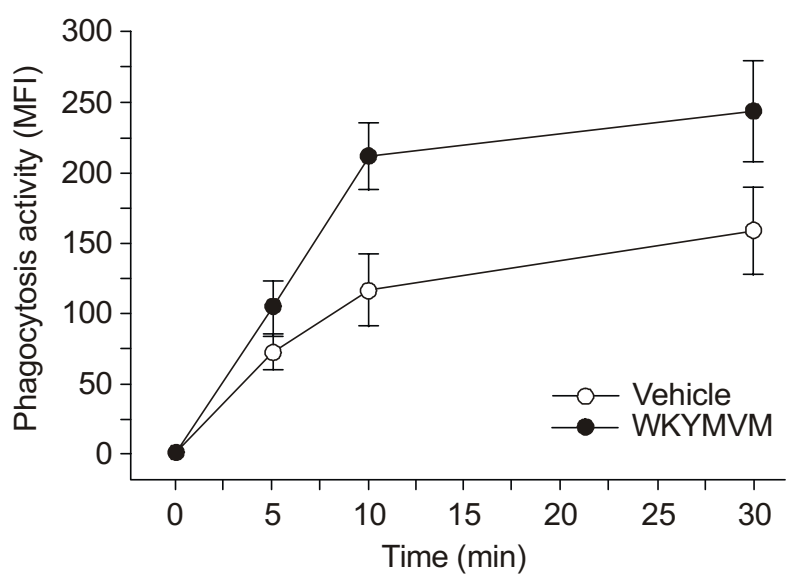

Figure 6. Enhancement of the DC phagocytosis by WKYMVM. DC2.4 cells $\left(1 \times 10^{5}\right)$ were incubated with $1 \mathrm{mg} / \mathrm{ml}$ of FITC-dextran in 500 $\mu$ of PBS containing $1 \%$ human serum at $37^{\circ} \mathrm{C}$ in the presence or absence of $1 \mu \mathrm{M}$ WKYMVM for several periods of time $(0,5,10$, and $30 \mathrm{~min}$ ). After adding $2 \mathrm{ml}$ of ice-cold PBS containing $1 \%$ human serum and $0.02 \%$ sodium azide, the samples were washed three times with ice-cold PBS and analyzed by using FACScan flow cytometer. The mean fluorescence intensity (MFI) was measured. The data are presented as means $\pm S$.E. from three separate experiments. 
the DC2.4 cells (Figure 5B).

\section{WKYMVM stimulates phagocytic activity of DC2.4 cells}

One of the important functions of iDCs is phagocytosis of pathogens or dying cells. Regulating the phagocytic activity is crucial for the efficient processing of the antigens and the presentation of the processed antigenic peptides by the MHC molecule (Guermonprez et al., 2002; Granucci et al., 2003). To assess the effect of FPR2 activation on the DC2.4 cells, the phagocytic activity was measured by using FITC-dextran. When FITC-dextran was added to the
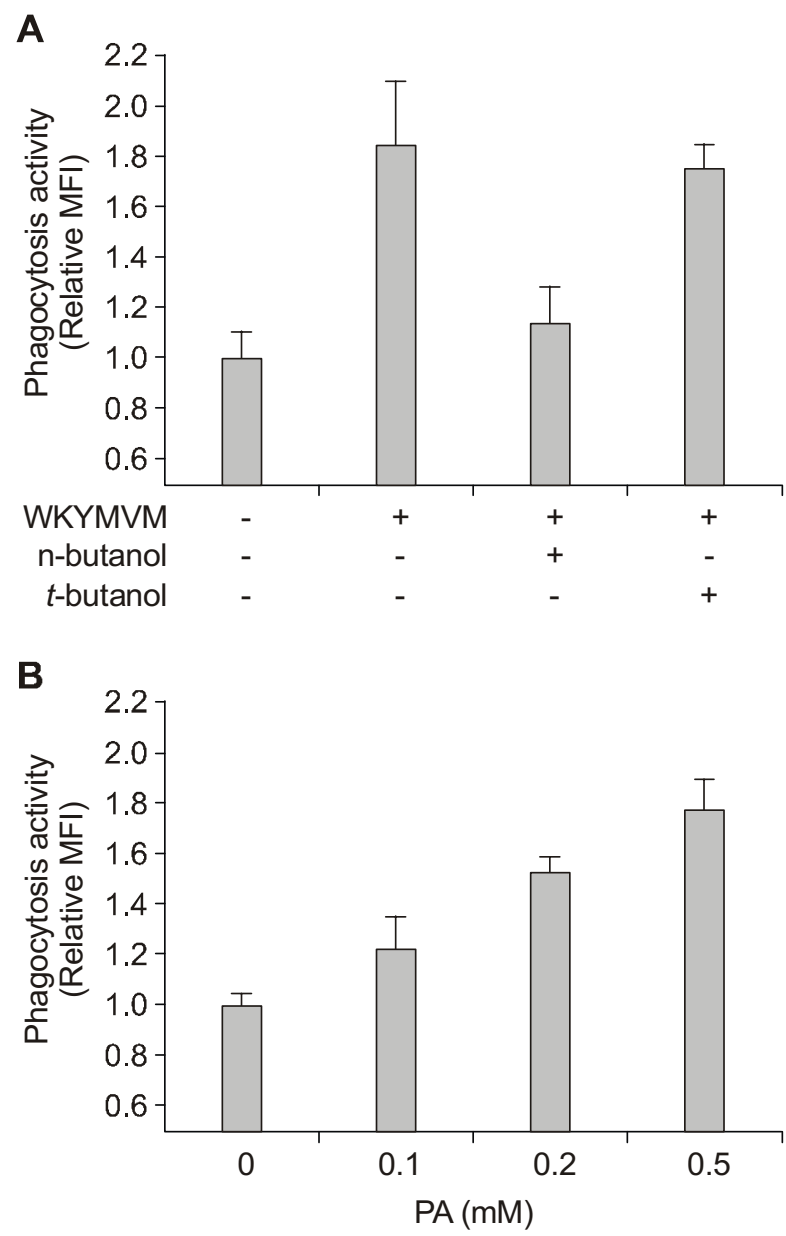

Figure 7. The role of PLD on the WKYMVM-induced DC phagocytosis. The phagocytic activity was measured as described in "Materials and Methods." The DC2.4 cells $\left(1 \times 10^{5}\right)$ were stimulated with $1 \mu \mathrm{M}$ WKYMVM in the presence of $0.5 \%$ n-butanol or $0.5 \%$ t-butanol for $10 \mathrm{~min}$ at $37^{\circ} \mathrm{C}(\mathrm{A})$. The DC2.4 cells $\left(1 \times 10^{5}\right)$ were stimulated with various $\mathrm{PA}$ concentrations for $10 \mathrm{~min}$ at $37^{\circ} \mathrm{C}$ (B). The uptaken FITC-dextran by DC2.4 cells were analyzed using FACScan flow cytometry. The mean fluorescence intensity (MFI) was measured. The data are presented means $\pm S$.E. from three separate experiments.
DC2.4 cells, the cells spontaneously induced phagocytosis in a time-dependent manner (Figure 6). Stimulating the DC2.4 cells with $1 \mu \mathrm{M}$ of WKYMVM significantly increased the phagocytic activity of the DC2.4 cells (Figure 6). This WKYMVM-induced enhancement of phagocytic activity was apparent within 5-30 min after adding the FITC-dextran (Figure 6).

\section{WKYMVM-stimulated phagocytic activity is PLD-mediated}

Several studies have reported that PA, a product of phosphatidylcholine hydrolysis by PLD, is involved in the modulating the leukocyte functions (Bae et al., 1999; Giron-Calle and Froman, 2000; Kaldi et al., 2002). In this study we tested whether or not PLD is involved in the WKYMVM-stimulated phagocytic activity in DC2.4 cells using n-butanol. In the transphosphatidyl reaction, a primary alcohol such as n-butanol acts as a PA acceptor resulting in the production phosphatidylalcohol instead of PA, while a non-primary alcohol such as tertiary butanol ( $t$ butanol) does not, thereby allowing PA production (Bae et al., 1999). WKYMVM stimulated the formation of $\mathrm{PBt}$ in the presence of $0.5 \% \mathrm{n}$-butanol in the DC2.4 cells, as shown in Figure 4A, while the PA formation during treatment with WKYMVM was not blocked in the presence of $0.5 \% t$-butanol. Figure $7 \mathrm{~A}$ shows that the WKYMVM-induced phagocytic activity of the DC2.4 cells was almost totally inhibited in the presence of $0.5 \%$ n-butanol but not in the presence of $0.5 \% t$-butanol. These results suggest that PA production is essential for the phagocytic activity in DC2.4 cells. In order to support the hypothesis that PLD activation is essential for the phagocytic activity, we investigated the direct effect of PA on the phagocytosis of the DC2.4 cells. As shown in Figure $7 B$, the addition of PA in the DC2.4 cells caused an apparent increase in the phagocytic activity of the

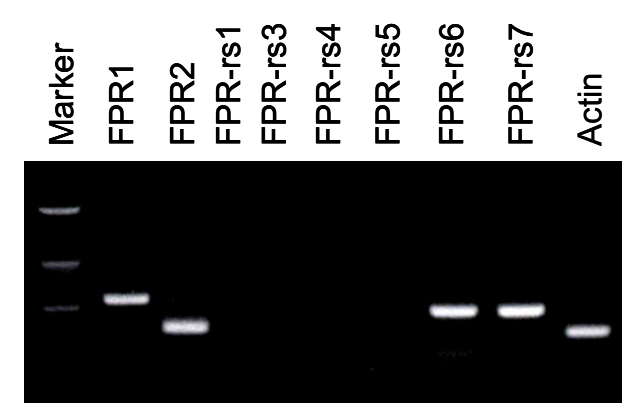

Figure 8. RT-PCR analysis of FPR family receptors in mouse bone marrow-derived DCs. RT-PCR analysis was performed on the mRNA isolated from the mouse bone marrow-derived DCs, as described in "Materials and Methods." The result presented is representative of three independent experiments. 
cells. Therefore, the results suggest that WKYMVM stimulates the phagocytic activity of the DC2.4 cells via PLD activation.

\section{Mouse bone marrow-derived DCs express FPR1 and FPR2}

To support our notion that WKYMVM stimulates primary mouse DCs, we analyzed expression of mRNA for the different FPR family receptors in primary mouse bone marrow-derived DCs using semiquantitative RT-PCR analysis. As shown in Figure 8, primary mouse bone marrow-derived DCs expressed both FPR1 and FPR2. Unlike to the DC2.4 cells primary mouse DCs expressed two other FPR family receptors, FPR-rs6 and FPR-rs7.

\section{Discussion}

DCs have important role in immune responses against invading microbial pathogens, apoptotic cells and tumors. In order to perform these immunological functions, DCs have to uptake the antigens necessary for the initiation of immune responses. In this study we demonstrate that a synthetic chemoattractant peptide WKYMVM enhances phagocytic activity in mouse DCs, DC2.4. This result suggests that WKYMVM act as an important functional modulator of DCs. The investigation of the signaling leading to the enhancement of phagocytic activity in DC2.4 cells after peptide stimulation revealed that the peptide-induced phagocytic activity is PLD-dependent.

Although the phagocytic activity of $D C$ is a crucial step for regulating the DC-mediated immune responses, the molecular mechanism involved in the process is not clearly understood. In this study we demonstrated that activating the phagocytosis of DC by WKYMVM is completely inhibited by the addition of $\mathrm{n}$-butanol but not $t$-butanol. The result suggests that PLD activation by WKYMVM is essential for the phagocytic activity in the DCs. Since PA generation is the primary consequence of PLD activation (Lennartz, 1999; Cockcroft, 2001), investigation on the effect of the exogenous addition of PA on the phagocytic activity of DC2.4 cells was carried out. The phagocytic activity in the DC2.4 cells was indeed enhanced by the exogenously added PA (Figure 7B), supporting the hypothesis that PLD activation is necessary for the phagocytic activity in DC2.4 cells. Previously several reports suggested that the activation of PLD is essentially coupled to the phagocytosis in phagocytic cells, such as macrophages and neutrophils (Fallman et al., 1992; Kusner et al., 1996). In the process of phagocytosis of Mycobacterium tuberculosis or opsonized zymosan by macrophages, the inhibition of PLD by 2,3-diphosphoglycerate (a
PLD inhibitor) (Kanaho et al., 1993) resulted in concentration-dependent reduction in phagocytosis (Kusner et al., 1996). Furthermore, the phagocytosis of $M$. tuberculosis of 2,3-diphosphoglycerate treated macrophage was restored by addition of purified PLD (Kusner et al., 1996). Fallman et al. demonstrated that the activation of PLD can act as an important signal regulating the engulfment of complement opsonized particles in the downstream of the signaling pathway of complement receptor type 1 and complement receptor type 3 in human neutrophils (Fallman et al., 1993). Recently, Jackson and colleagues demonstrated that the PLD activation induced by Fc $\gamma$ receptor regulates macrophage phagocytosis, by showing that phagocytosis of IgG-coated sheep red blood cells was inhibited by two inhibitors of PLD-mediated signaling, 2,3-diphosphoglycerate and n-butanol (Kusner et al., 1999). The PA-activated protein kinases have been suggested to perform a role in the mechanism involved in regulating PA-mediated macrophage phagocytosis (Kusner et al., 1999). We also observed that stimulating the DC2.4 cells with WKYMVM caused a dramatic increase in the tyrosine phosphorylation levels of several cellular proteins, including $120 \mathrm{kDa}$, $68 \mathrm{kDa}$, and $50 \mathrm{kDa}$ (data not shown). The WKYMVMinduced tyrosine phosphorylation of the proteins was inhibited by the addition of $0.5 \%$ n-butanol but not $0.5 \%$-butanol (data not shown). The results suggest that several tyrosine kinases can be activated by WKYMVM via the PLD-mediated signaling pathway and potentially be involved in the regulation of $D C$ phagocytosis.

On the cell surface receptors involved in the WKYMVM-induced phagocytic activity in mouse DCs, we demonstrated that DC2.4 mouse DCs express two FPR family receptors, FPR1 and FPR2 (Figure 2). Previously, Dahlgren and colleagues demonstrated that WKYMVM binds to FPRL1 and FPRL2 but not FPR (Christophe et al., 2001). We also confirmed that primary mouse DCs express several different FPR family receptors using semiquantitative RT-PCR analysis (Figure 8). Taken together, the results suggest that WKYMVM may enhance the phagocytic activity of mouse DCs via activation of FPR family. Considering that the phagocytic activity by the DCs is an important initial step in the immune responses against the infected pathogens or tumor antigens, the identification of receptor which is crucial for the WKYMVMinduced phagocytosis in DCs will be important. Furthermore, the receptor will be regarded to be crucial target for modulating immune responses.

\section{Acknowledgement}

This work was supported by a grant 02-PJ1-PG321202-0003 from the Korea Health 21 R\&D Project, Ministry of Health and Welfare, Republic of Korea. 


\section{References}

Bae YS, Ju SA, Kim JY, Seo JK, Baek SH, Kwak JY, Kim BS, Suh PG, Ryu SH. Trp-Lys-Tyr-Met-Val-D-Met stimulates superoxide generation and killing of Staphylococcus aureus via phospholipase $\mathrm{D}$ activation in human monocytes. J Leukoc Biol 1999;65:241-8

Bae YS, Kim Y, Kim JH, Lee TG, Suh PG, Ryu SH. Independent functioning of cytosolic phospholipase $\mathrm{A} 2$ and phospholipase D1 in Trp-Lys-Tyr-Met-Val-D-Met-induced superoxide generation in human monocytes. J Immunol 2000; 164:4089-96

Bae YS, Bae H, Kim Y, Lee TG, Suh PG, Ryu SH. Identification of novel chemoattractant peptides for human leukocytes. Blood 2001a;97:2854-62

Bae YS, Ryu SH. ATP-induced focal adhesion kinase activity is negatively modulated by phospholipase D2 in PC12 cells. Exp Mol Med 2001b;33:150-5

Baek SH, Seo JK, Chae CB, Suh PG, Ryu SH. Identification of the peptides that stimulate the phosphoinositide hydrolysis in lymphocyte cell lines from peptide libraries. J Biol Chem 1996;271:8170-5

Baek SH, Bae YS, Seo JK, Lee YH, Kim JH, Kwun KB, Suh PG, Ryu SH. Trp-Lys-Tyr-Met-Val-Met activates mitogen-activated protein kinase via a $\mathrm{Pl}-3$ kinase-mediated pathway independent of PKC. Life Sci 1999;65:1845-56

Christophe T, Karlsson A, Dugave C, Rabiet MJ, Boulay F, Dahlgren $C$. The synthetic peptide Trp-Lys-Tyr-Met-Val-Met$\mathrm{NH} 2$ specifically activates neutrophils through FPRL1/lipoxin A4 receptors and is an agonist for the orphan monocyte-expressed chemoattractant receptor FPRL2. J Biol Chem 2001;276:21585-93

Cockcroft S. Signalling roles of mammalian phospholipase D1 and D2. Cell Mol Life Sci 2001;58:1674-87

Colley WC, Sung TC, Roll R, Jenco J, Hammond SM, Altshuller Y, Bar-Sagi D, Morris AJ, Frohman MA. Phospholipase D2, a distinct phospholipase $D$ isoform with novel regulatory properties that provokes cytoskeletal reorganization. Curr Biol 1997;7:191-201

Fallman M, Gullberg M, Hellberg C, Andersson T. Complement receptor-mediated phagocytosis is associated with accumulation of phosphatidylcholine-derived diglyceride in human neutrophils. Involvement of phospholipase D and direct evidence for a positive feedback signal of protein kinase. J Biol Chem 1992;267:2656-63

Fallman M, Andersson R, Andersson T. Signaling properties of CR3 (CD11b/CD18) and CR1 (CD35) in relation to phagocytosis of complement-opsonized particles. J Immunol. 1993;151:330-8

Fillion I, Ouellet N, Simard M, Bergeron Y, Sato S, Bergeron $M$. Role of chemokines and formyl peptides in pneumococcal pneumonia-induced monocyte/macrophage recruitment. J Immunol 2001;166:7353-61

Gao JL, Lee EJ, Murphy PM. Impaired antibacterial host defense in mice lacking the $\mathrm{N}$-formylpeptide receptor. J Exp Med 1999;189:657-62

Giron-Calle J, Forman HJ. Phospholipase D and priming of the respiratory burst by $\mathrm{H}(2) \mathrm{O}(2)$ in NR8383 alveolar macrophages. Am J Respir Cell Mol Biol 2000;23:748-54

Granucci F, Zanoni I, Feau S, Ricciardi-Castagnoli P. Dendritic cell regulation of immune responses: a new role for interleukin 2 at the intersection of innate and adaptive immunity. EMBO J 2003;22:2546-51

Guermonprez P, Valladeau J, Zitvogel L, Thery C, Amigorena $\mathrm{S}$. Antigen presentation and $\mathrm{T}$ cell stimulation by dendritic cells. Annu Rev Immunol 2002;20:621-67

Hammond SM, Altshuller YM, Sung TC, Rudge SA, Rose $\mathrm{K}$, Engebrecht J, Morris AJ, Frohman MA. Human ADPribosylation factor-activated phosphatidylcholine-specific phospholipase $D$ defines a new and highly conserved gene family. J Biol Chem 1995;270:29640-3

Hartt JK, Liang T, Sahagun-Ruiz A, Wang JM, Gao JL, Murphy PM. The HIV-1 cell entry inhibitor T-20 potently chemoattracts neutrophils by specifically activating the $\mathrm{N}$ formylpeptide receptor. Biochem Biophys Res Commun 2000;272:699-704

He R, Tan L, Browning DD, Wang JM, Ye RD. The synthetic peptide Trp-Lys-Tyr-Met-Val-D-Met is a potent chemotactic agonist for mouse formyl peptide receptor. J Immunol 2000;165:4598-605

Hu JY, Le Y, Gong W, Dunlop NW, Gao JL, Murphy PM, Wang JM. Synthetic peptide MMK-1 is a highly specific chemotactic agonist for leukocyte FPRL1. J Leukoc Biol 2001;70:155-61

Kaldi K, Szeberenyi J, Rada BK, Kovacs P, Geiszt M, Mocsai A, Ligeti E. Contribution of phopholipase $D$ and a brefeldin A-sensitive ARF to chemoattractant-induced superoxide production and secretion of human neutrophils. J Leukoc Biol 2002;71:695-700

Kanaho Y, Nakai Y, Katoh M, Nozawa Y. The phosphatase inhibitor 2,3-diphosphoglycerate interferes with phospholipase $D$ activation in rabbit peritoneal neutrophils. J Biol Chem 1993;268:12492-7

Kim HS, Song M, Kim E, Ryu SH, Suh PG. Dexamethasone differentiates NG108-15 cells through cyclooxygenase 1 induction. Exp Mol Med 2003;35:203-10

Kim YR, Cha HY, Lim K, Hwang BD, Hoe KL, Namgung $U$, Park SK. Activation of epidermal growth factor receptor is responsible for pervanadate-induced phospholipase $D$ activation. Exp Mol Med 2003;35:118-24

King J, Laemmli UK. Polypeptides of the tail fibres of bacteriophage T4. J Mol Biol 1971;62:465-77

Kusner DJ, Hall CF, Schlesinger LS. Activation of phospholipase $D$ is tightly coupled to the phagocytosis of Mycobacterium tuberculosis or opsonized zymosan by human macrophages. J Exp Med 1996;184:585-95

Kusner DJ, Hall CF, Jackson S. Fc gamma receptormediated activation of phospholipase $D$ regulates macrophage phagocytosis of IgG-opsonized particles. J Immunol 1999;162:2266-74

Le Y, Gong W, Li B, Dunlop NM, Shen W, Su SB, Ye RD, Wang JM. Utilization of two seven-transmembrane, $G$ protein-coupled receptors, formyl peptide receptor-like 1 and formyl peptide receptor, by the synthetic hexapeptide 
WKYMVm for human phagocyte activation. J Immunol 1999; 163:6777-84

Lee TG, Park JB, Lee SD, Hong S, Kim JH, Kim Y, Yi KS, Bae S, Hannun YA, Obeid LM, Suh PG, Ryu SH. Phorbol myristate acetate-dependent association of protein kinase $C$ alpha with phospholipase D1 in intact cells. Biochim Biophys Acta 1997;1347:199-204

Lennartz MR. Phospholipases and phagocytosis: the role of phospholipid-derived second messengers in phagocytosis. Int J Biochem Cell Biol 1999;31:415-30

Li S, Yamauchi A, Marchal CC, Molitoris JK, Quilliam LA, Dinauer MC. Chemoattractant-stimulated Rac activation in wild-type and Rac2-deficient murine neutrophils: preferential activation of Rac2 and Rac2 gene dosage effect on neutrophil functions. J Immunol 2002;169:5043-51

Liang TS, Wang JM, Murphy PM, Gao JL. Serum amyloid $A$ is a chemotactic agonist at FPR2, a low-affinity Nformylpeptide receptor on mouse neutrophils. Biochem Biophys Res Commun 2000;270:331-5

Melendez AJ, Bruetschy L, Floto RA, Harnett MM, Allen JM. Functional coupling of FcgammaRI to nicotinamide adenine dinucleotide phosphate (reduced form) oxidative burst and immune complex trafficking requires the activation of phospholipase D1. Blood 2001;98:3421-8

Milella M, Gismondi A, Roncaioli P, Palmieri G, Morrone S, Piccoli M, Frati L, Cifone MG, Santoni A. Beta 1 integrin cross-linking inhibits CD16-induced phospholipase $D$ and secretory phospholipase A2 activity and granule exocytosis in human NK cells: role of phospholipase D in CD16triggered degranulation. J Immunol 1999;162:2064-72

Seo JK, Choi SY, Kim Y, Baek SH, Kim KT, Chae CB,
Lambeth JD, Suh PG, Ryu SH. A peptide with unique receptor specificity: stimulation of phosphoinositide hydrolysis and induction of superoxide generation in human neutrophils. J Immunol 1997;158:1895-901

Shen Z, Reznikoff G, Dranoff G, Rock KL. Cloned dendritic cells can present exogenous antigens on both MHC class I and class II molecules. J Immunol 1997;158:2723-30

Shin JY, Lee SK, Kang CD, Chung JS, Lee EY, Seo SY, Lee SY, Baek SY, Kim BS, Kim JM, Yoon S. Antitumor effect of intratumoral administration of dendritic cell combination with vincristine chemotherapy in a murine fibrosarcoma model. Histol Histopathol 2003;18:435-47

Tiffany $\mathrm{HL}$, Lavigne MC, Cui $\mathrm{YH}$, Wang JM, Leto TL, Gao $\mathrm{JL}$, Murphy PM. Amyloid-beta induces chemotaxis and oxidant stress by acting at formylpeptide receptor 2, a G protein-coupled receptor expressed in phagocytes and brain. $\mathrm{J}$ Biol Chem 2001;276:23645-52

Wang ZG, Ye RD. Characterization of two new members of the formyl peptide receptor gene family from $129 S 6$ mice. Gene 2002;299:57-63

Xia CQ, Kao KJ. Heparin induces differentiation of CD1a+ dendritic cells from monocytes: phenotypic and functional characterization. J Immunol 2002;168:1131-8

Yang D, Chen Q, Le Y, Wang JM, Oppenheim JJ. Differential regulation of formyl peptide receptor-like 1 expression during the differentiation of monocytes to dendritic cells and macrophages. J Immunol 2001;166:4092-8

Yang D, Chen Q, Gertz B, He R, Phulsuksombati M, Ye RD, Oppenheim JJ. Human dendritic cells express functional formyl peptide receptor-like-2 (FPRL2) throughout maturation. J Leukoc Biol 2002;72:598-607 